\title{
Serotonin-2 Receptors and Human Sleep: Effect of a Selective Antagonist on EEG Power Spectra
}

Hans-Peter Landolt, Ph.D., Viola Meier, Helen J. Burgess, Ph.D., Luca A. Finelli, Françoise Cattelin, M.D., Peter Achermann, Ph.D., and Alexander A. Borbély, M.D.

To investigate the effect on the sleep EEG, a 1-mg oral dose of SR 46349B, a novel 5-HT ${ }_{2}$ antagonist, was administered three hours before bedtime. The drug enhanced slow wave sleep (SWS) and reduced stage 2 without affecting subjective sleep quality. In nonREM sleep (NREMS) EEG slow-wave activity (SWA; power within 0.75-4.5 Hz) was increased and spindle frequency activity (SFA; power within $12.25-15 \mathrm{~Hz}$ ) was decreased. The relative NREMS power spectrum showed a bimodal pattern with the main peak at $1.5 \mathrm{~Hz}$ and a secondary peak at $6 \mathrm{~Hz}$. A regional analysis based on bipolar derivations along the anteroposterior axis revealed significant 'treatment' $\times$ 'derivation' interactions within the 9-16 Hz range. In enhancing SWA and attenuating SFA, the $5-\mathrm{HT}_{2}$ receptor antagonist mimicked the effect of sleep deprivation, whereas the pattern of the NREMS spectrum differed.

[Neuropsychopharmacology 21:455-466, 1999] (C) 1999 American College of Neuropsychopharmacology. Published by Elsevier Science Inc.
KEY WORDS: Slow wave sleep; REM sleep; Sleep deprivation; Slow-wave activity; Spindle frequency activity; Regional differences

The pivotal role of serotonin (5-hydroxytryptamine, 5-HT) in sleep regulation has been the mainstay of the monoamine theory of sleep (Jouvet 1972). Although the views about the functions of this neurotransmitter have evolved, there is little doubt about its involvement in sleep mechanisms (McCormick 1992). Serotonergic neurons of the nucleus raphe dorsalis are most active during wakefulness and have been proposed to participate in the build-up of sleep propensity (Adrien 1995). Ani-

From the Institute of Pharmacology, University of Zürich, Zürich, Switzerland (H-PL, VM, HJB, LAF, PA, AAB), and SANOFI Recherche, Montpellier Cédex 4, France (FC).

Address correspondence to: Hans-Peter Landolt, Ph.D., University of California at San Diego, Psychiatry Service (116-A), Veterans Affairs Medical Center, 3350 La Jolla Village Drive, San Diego, CA 92161.

Received December 9, 1998; revised March 15, 1999; accepted April 9, 1999. mal studies revealed that these neurons decrease firing upon transition from wakefulness to nonREM sleep (NREMS), and become quiescent during REM sleep (REMS). Thus, deactivation of the serotonergic system may facilitate the production of NREMS and REMS (Adrien 1995). One of the complexities in accounting for the actions of 5-HT is the large number of different receptors and receptor subtypes. 5-HT receptors are classified into four distinct classes, comprising seven fully characterized functional receptor subtypes and several recombinant receptors (Hoyer and Martin 1996). While the involvement of three main classes (i.e., $5-\mathrm{HT}_{1}, 5-\mathrm{HT}_{2}$, and $5-\mathrm{HT}_{3}$ receptors) in the regulation of sleep and wakefulness has been studied, it is the postsynaptic $5-\mathrm{HT}_{1 \mathrm{~A}}$ receptor that seems to mediate the inhibition of REMS and the promotion of wakefulness, whereas activation of the $5-\mathrm{HT}_{2}$ receptor may exert a tonic inhibition of slow wave sleep (SWS) (see Adrien 1995 for review). In relation to sleep homeostasis, the latter is of particular interest because 5- $\mathrm{HT}_{2}$ antagonists were shown to increase the amount of SWS and to enhance EEG slow- 
wave activity (SWA; power within $0.75-4.5 \mathrm{~Hz}$ ) in humans and animals (Idzikowski et al. 1986; Borbély et al. 1988; Dijk et al. 1989). The 5- $\mathrm{HT}_{2}$ receptor family is subdivided into three specific subtypes (i.e., $5-\mathrm{HT}_{2 \mathrm{~A}}, 5-\mathrm{HT}_{2 \mathrm{~B}}$, and $5-\mathrm{HT}_{2 \mathrm{C}}$ receptors) (Humphrey et al. 1993). Whereas it is not clear whether $5-\mathrm{HT}_{2 \mathrm{~B}}$ binding sites are present in the human brain, the $5-\mathrm{HT}_{2 \mathrm{~A}}$ subtype may be identical with the classical 5- $\mathrm{HT}_{2}$ receptor. However, 5- $\mathrm{HT}_{2 \mathrm{C}}$ receptors have been proposed to play a more important role in the regulation of SWS than $5-\mathrm{HT}_{2 \mathrm{~A}}$ receptors (Sharpley et al. 1994).

SWA represents a physiological marker of the homeostatic facet of sleep regulation (Borbély and Tononi 1998). It shows typically a declining trend across successive NREMS episodes and has been considered to be an indicator of NREMS intensity. Sleep loss enhances SWA and daytime sleep attenuates it (Borbély et al. 1981; Aeschbach et al. 1996; Werth et al. 1996). During the transition from waking to sleep, the activity of the ascending monoaminergic reticular pathways is progressively reduced which leads to a hyperpolarization of thalamocortical neurons (McCormick and Bal 1997). A moderate hyperpolarization results in fluctuations of the membrane potential in the frequency range of sleep spindles, whereas a strong hyperpolarization gives rise to fluctuations in the slow-wave range (Steriade et al. 1993, 1994). These changes at the cellular level are mirrored by the sleep EEG, which exhibits sleep spindles in stage 2 of NREMS and slow waves during deep NREMS (i.e., stages 3 and 4). Application of 5-HT to thalamocortical neurons may block rhythmic burst firing and suppress slow synchronized oscillations (McCormick 1992). Animal studies suggest that these effects are mediated via $5-\mathrm{HT}_{2}$ receptors (McCormick and Wang 1991; Bobker 1994).

It was shown repeatedly that the physiological enhancement of "sleep pressure" by sleep deprivation enhances power density in the entire delta and theta frequency range $(\sim 0.5-10 \mathrm{~Hz})$, whereas power in the frequency band of sleep spindles $(12-15.0 \mathrm{~Hz})$ is reduced (Borbély et al. 1981; Dijk et al. 1990, 1993; Aeschbach et al. 1996). Both SWA and spindle frequency activity (SFA, power within 12.25-15.0 Hz) were shown to rise more rapidly than in baseline in the beginning of recovery sleep (Dijk et al. 1990; Aeschbach et al. 1996). Recent studies demonstrated that these EEG changes reflecting sleep regulatory mechanisms show distinct regional differences. Thus in the first two sleep cycles, SWA recorded from frontal derivations was more prominent than SWA from more posterior derivations, a difference that vanished in the later sleep cycles (Werth et al. 1997). The possibility that restorative processes of NREMS are most intense over the frontal cortex is also supported by a sleep deprivation experiment (Werth et al. 1998). These observations prompted us to perform a topographical analysis in the present study and to see whether interference with the serotonergic system has specific regional effects.

The development of specific 5- $\mathrm{HT}_{2}$ receptor antagonists provided new tools to investigate the role of the serotonergic system in sleep regulation. SR 46349B is a novel, potent and selective $5-\mathrm{HT}_{2 \mathrm{~A}}$ receptor antagonist in rodents (Rinaldi-Carmona et al. 1992). It was administered to healthy young subjects to investigate its effects on the sleep EEG and to compare them with the changes that had been previously observed after sleep deprivation. The main question addressed in the present study was whether this $5-\mathrm{HT}_{2}$ antagonist mimics the effects of physiological sleep intensification. In view of the close association between body temperature and sleep regulation, and the involvement of central $5-\mathrm{HT}_{2}$ receptors in thermoregulation (Schwartz et al. 1995), rectal temperature was measured during all sleep episodes.

\section{METHODS}

\section{Subjects and study protocol}

Male volunteers from the student populations of the University of Zürich and the Swiss Federal Institute of Technology were recruited for participation in this study. After a telephone screening, they were invited to the sleep laboratory to complete a questionnaire on subjective sleep quality, current sleep-wake habits, medical history, and the use of caffeine and ethanol. They all reported being good sleepers, being in good health and were not taking any medication or consuming any illicit drugs. They underwent a physical examination including routine screening laboratory tests of blood and urine. They were asked to keep a sleep-, caffeine-, and ethanol-log during one week. Subsequently, the subjects were screened by polysomnography in the sleep laboratory to exclude sleep disturbances such as sleep apnea and nocturnal myoclonus. Written informed consent was obtained prior to the screening night. Subjects with sleep apnea, a nocturnal myoclonus-index of ten or more per hour of sleep, and a sleepefficiency of less than $70 \%$ were excluded. Ten healthy, right-handed men with a mean age of $22.0 \pm 0.3$ (SEM) years (range: $20-25$ years) and a mean body-mass index (BMI) of $21.5 \pm 1.2(\mathrm{SEM}) \mathrm{kg} / \mathrm{m}^{2}$ (range: $19.7-24.1 \mathrm{~kg}$ / $\mathrm{m}^{2}$ ) were selected and paid for participation. Their diaries and questionnaires revealed regular time in bed between approximately 2300 and $0700 \mathrm{hrs}$ and no subjective sleep disturbances. All subjects were nonsmokers and reported a consumption of less than eight alcoholic drinks per week, and less than three caffeine-containing beverages (coffee, tea, cola drinks) per day. At least three days prior to each sleep recording and during the experiment, the subjects were asked to abstain from 
ethanol and caffeine. During the pre-study week, they also were instructed to keep a regular sleep-wake cycle with sleep scheduled from 2300 to 0700 hrs. Compliance with these instructions was verified on the basis of records from activity monitors worn on the wrist of the non-dominant arm as well as by determination of the breath-ethanol concentration and the level of caffeine in saliva upon arrival in the sleep laboratory (at approximately $1930 \mathrm{hrs}$ ). Breath-ethanol concentrations were measured with a Lion Alcometer S-D2 (Lion Laboratories plc., Barry, Wales, UK). Saliva samples were stored at $-20^{\circ} \mathrm{C}$ and later assayed for caffeine with an $\mathrm{EMIT}^{\Theta_{-}}$ Caffeine Test (Syva Company, Palo Alto, CA). The caffeine level in the subjects' saliva was invariably below the limit of detection $(1.0 \mu \mathrm{mol} / \mathrm{l})$ and no ethanol in their breath was detected.

The study protocol was approved by the local ethical committee for research on human subjects and consisted of two sessions of two consecutive nights. On each session, an adaptation night was followed by an experimental night. Subjects slept in the completely dark and sound attenuated bedrooms of the sleep laboratory from 2300 to $0700 \mathrm{hrs}$. At $2000 \mathrm{hrs}$ prior to the scheduled experimental nights they received a tablet which either contained $1 \mathrm{mg}$ SR46349B or placebo (manufacturer: SANOFI Recherche, Montpellier Cédex 4, France). Thus, a single oral dose of SR 46349B was administered to each subject according to a randomized, placebo-controlled, double-blind, cross-over design. A 1-mg dose was chosen on the basis of previous, unpublished dose-response studies.

Fifteen minutes after awakening, subjective sleep quality (estimated sleep latency, perceived number of awakenings, estimated wake duration after sleep onset, sound vs. fragmented sleep, and superficial vs. deep sleep) and self-rated state (recuperated vs. tired, bad mood vs. good mood, lack of energy vs. full of energy, tense vs. relaxed, and unable to concentrate vs. able to concentrate) were assessed by a questionnaire and $100-\mathrm{mm}$ on some live visual analogue scales.

\section{Polygraphic recordings, heart rate and core body temperature}

The electroencephalogram (EEG), electrooculogram (EOG), submental electromyogram (EMG), electrocardiogram (ECG), and rectal temperature were recorded by a polygraphic amplifier (PSA24, Braintronics Inc., Almere, The Netherlands), digitized, and transmitted via fiber-optic cables to a personal computer. EEG electrodes were placed at the locations F3, F4, C4, P3, P4, $\mathrm{O} 1, \mathrm{O} 2, \mathrm{Cz}$, and $\mathrm{A} 2$, and referenced against C3. EEG, EOG, and EMG signals were conditioned by the following analogue filters: a high-pass filter $(-3 \mathrm{~dB}$ at 0.16 $\mathrm{Hz})$, a low-pass filter $(-3 \mathrm{~dB}$ at $102 \mathrm{~Hz},<-40 \mathrm{~dB}$ at 256
$\mathrm{Hz})$, and a notch filter $(50 \mathrm{~Hz})$. Data were sampled with a frequency of $512 \mathrm{~Hz}$, digitally filtered (EEG: low-pass FIR filter, $-3 \mathrm{~dB}$ at $49 \mathrm{~Hz}$; EMG: band-pass FIR filter, $-3 \mathrm{~dB}$ at 15.6 and $54 \mathrm{~Hz}$ ), and stored on hard-disk with a resolution of $128 \mathrm{~Hz}$. Subsequently, power spectra for consecutive 4-s epochs, weighted by application of a $10 \%$ cosine window, were computed by a Fast-Fourier transform routine, resulting in a frequency resolution of $0.25 \mathrm{~Hz}$. Values above $25 \mathrm{~Hz}$ were omitted. Sleep stages were visually scored from the records of the C3A2 derivation for consecutive 20-s epochs according to the criteria of Rechtschaffen and Kales (1968). Power spectra of five consecutive 4-s epochs were averaged and matched with the sleep scores. Four-s epochs with artifacts were identified and eliminated. Consecutive NREM-REMS cycles were defined according to modified criteria of Feinberg and Floyd (1979). NREMS episodes starting with stage 2 and containing at least 15 minutes of the stages 2, 3 and 4 were succeeded by REMS episodes of at least 5 minutes duration. For the completion of the first cycle no minimal criterion for the REMS duration was applied. With the exception of two sleep episodes, at least four NREM-REMS cycles were completed in all experimental nights.

Regional differences were investigated by comparing the spectra of the bipolar derivations along the antero-posterior axis. Due to artifacts, the data of two subjects had to be excluded from the topographical analyses.

One value of heart rate (beats per minute, as calculated from the mean time interval between consecutive $\mathrm{R}$-waves) and one value of core body temperature were stored every $20 \mathrm{sec}$. Due to technical problems the temperature data of two subjects were lost.

\section{Statistics}

For statistical analyses the SAS General Linear Model procedure (SAS Institute Inc., Cary, NC) with Greenhouse-Geisser correction was used (if a factor had more than two levels). Visually scored sleep variables, EEG power spectra in NREMS and REMS, the time course and evolution of SWA and in the first four NREMS episodes, and regional differences of EEG spectra were analyzed. Significant effects of the treatment and differences between bipolar derivations were assessed using one-, two-, and three-way analyses of variance for repeated measures (rANOVA). Statistical models included terms for the between factor 'sequence' and multiple within factors as described in the Results section. The significance level was set at $\mathrm{p}<0.05$. To approximate the normal distribution, values of sleep latency, REMS latency, absolute power densities and ratios of power densities between derivations were logtransformed prior to statistical tests. 


\section{RESULTS}

\section{Sleep variables derived from visual scoring and subjective sleep quality}

The major change induced by the drug consisted of the large increase of SWS as well as its constituent stages 3 and 4 (Table 1 and Table 2). While the enhancement of SWS reached the highest level in the second NREMS episode, it was increased in each of the first three episodes. In contrast, stage 2 was reduced in the second NREMS episode. Waking after sleep onset and the combined arousal variable (wakefulness + movement time + stage 1) did not differ significantly from the placebo level, but movement time was reduced. There was no significant difference in the all-night duration of REMS. However, when expressed as a percentage of total sleep time, REMS was decreased (Table 2). The duration of the second and the third NREMS episodes were prolonged (Table 1).

No significant differences between the placebo and treatment nights were observed for sleep episode, total sleep time, sleep efficiency, latency to stage 1, latency to stage 2, and REMS latency (Table 2).

State variables in the morning, and subjective sleep quality did not differ significantly between the treatments.

\section{EEG power spectra}

Figure 1 is a composite representation of the sleep stage profiles and EEG SWA from a subject after placebo (upper panel) and drug treatment (lower panel). Note the increase in stage 3 and 4 sleep and the concomitant enhancement of SWA in the drug night. The comparison of corresponding NREMS episodes reveals enhanced SWA in the second and following episodes. In the mean all-night power spectra shown in Figure 2, the values for the drug night are expressed as percentage of the placebo night. Power density values were averaged into $0.5-\mathrm{Hz}(0.25-5.0 \mathrm{~Hz})$ and $1.0-\mathrm{Hz}(5.25-25.0 \mathrm{~Hz})$ bins. The spectra were calculated separately for NREMS (stages 2,3 , and 4 ), stage 2, SWS, and REMS. The NREMS spectrum showed a bimodal pattern in the low-frequency

Table 1. Visually Scored Sleep Variables (min) and Heart Rate (bpm)

\begin{tabular}{|c|c|c|c|c|c|c|c|c|c|}
\hline \multirow[b]{2}{*}{ Variable } & \multirow[b]{2}{*}{ Treatment } & \multirow[b]{2}{*}{ Night } & \multicolumn{4}{|c|}{ NREM-REMS Cycle } & \multirow{2}{*}{$\begin{array}{c}\text { 'Treatment' } \\
\mathrm{F}_{1,8}(p)\end{array}$} & \multirow{2}{*}{$\begin{array}{l}\text { 'Cycle' } \\
\mathrm{F}_{3,24}(p)\end{array}$} & \multirow{2}{*}{$\begin{array}{l}\text { 'Treatment' } \times \\
\text { 'Cycle' } \mathrm{F}_{3,24}(p)\end{array}$} \\
\hline & & & 1 & 2 & 3 & 4 & & & \\
\hline \multirow[t]{2}{*}{ Cycle length } & Placebo & & $82.1(7.3)$ & $104.5(5.4)$ & $96.1(8.5)$ & $112.4(7.2)$ & $3.9(.10)$ & $3.7(.03)$ & $6.1(.02)$ \\
\hline & SR 46349B & & $82.1(3.9)$ & $123.6(6.0)$ & $127.9(8.5)$ & $92.5(3.5)^{d}$ & & & \\
\hline \multirow[t]{2}{*}{ NREM-Ep. } & Placebo & & $65.8(5.2)$ & $75.5(3.9)$ & $67.1(4.3)$ & $59.9(2.7)$ & $31.3(<.01)$ & $6.7(<.01)$ & $6.1(<.01)$ \\
\hline & SR 46349B & & $68.6(3.3)$ & $87.3(4.5)^{b}$ & $88.9(5.5)^{c}$ & $62.2(2.4)$ & & & \\
\hline \multirow[t]{2}{*}{ REM-Ep. } & Placebo & & $15.7(3.5)$ & $26.1(3.5)$ & $27.7(6.3)$ & $49.2(7.7)$ & $0.5(.53)$ & $7.5(<.01)$ & $2.4(.15)$ \\
\hline & SR 46349B & & $12.4(2.1)$ & $34.6(3.1)$ & $36.2(4.2)$ & $29.5(3.5)^{d}$ & & & \\
\hline \multirow[t]{2}{*}{ WASO } & Placebo & $16.3(6.4)$ & $1.9(1.4)$ & $0.2(0.2)$ & $0.4(0.2)$ & $7.6(5.9)$ & $1.2(.31)$ & $1.7(.23)$ & $0.8(.41)$ \\
\hline & SR 46349B & $6.8(2.6)$ & $0.3(0.2)$ & $0.3(0.2)$ & $0.8(0.5)$ & $2.6(1.1)$ & & & \\
\hline \multirow[t]{2}{*}{ Stage 1} & Placebo & $43.9(4.9)$ & $4.3(0.9)$ & $8.8(2.0)$ & $9.5(1.0)$ & $13.2(1.5)$ & $0.4(.57)$ & $12.8(<.01)$ & $0.5(.61)$ \\
\hline & SR 46349B & $37.3(3.5)$ & $2.9(0.6)$ & $7.6(1.0)$ & $11.4(1.9)$ & $12.0(2.5)$ & & & \\
\hline \multirow[t]{2}{*}{ Stage 2} & Placebo & $217.2(9.0)$ & $27.3(2.6)$ & $42.3(4.2)$ & $56.5(5.2)$ & $52.6(3.0)$ & $6.4(.04)$ & $21.9(<.01)$ & $6.4(<.01)$ \\
\hline & SR 46349B & $183.5(8.9)^{b}$ & $21.5(2.5)$ & $23.4(4.3)^{b}$ & $57.5(7.1)$ & $55.2(2.8)$ & & & \\
\hline \multirow[t]{2}{*}{ Stage 3} & Placebo & $45.3(4.0)$ & $16.2(1.9)$ & $17.2(2.3)$ & $5.6(1.8)$ & $2.9(1.2)$ & $39.8(<.01)$ & $20.1(<.01)$ & $11.9(<.01)$ \\
\hline & SR 46349B & $77.8(5.8)^{b}$ & $17.4(1.7)$ & $33.3(3.4)^{c}$ & $24.4(4.7)^{b}$ & $1.8(1.0)$ & & & \\
\hline \multirow[t]{2}{*}{ Stage 4} & Placebo & $36.8(4.4)$ & $19.2(2.6)$ & $14.4(3.8)$ & $2.1(1.4)$ & $0.0(0.0)$ & $29.4(<.01)$ & $24.5(<.01)$ & $10.5(<.01)$ \\
\hline & SR 46349B & $66.0(7.8)^{c}$ & $30.4(3.1)^{b}$ & $31.0(5.5)^{c}$ & $4.6(1.8)$ & $0.0(0.0)$ & & & \\
\hline \multirow[t]{2}{*}{ SWS } & Placebo & $82.2(4.9)$ & $35.4(2.9)$ & $31.6(3.7)$ & 7.7 (2.7) & $3.0(1.2)$ & $58.1(<.01)$ & $51.9(<.01)$ & $12.6(<.01)$ \\
\hline & SR 46349B & $143.8(10.5)^{c}$ & $47.8(2.6)^{b}$ & $64.3(5.4)^{c}$ & $29.0(5.7)^{b}$ & $1.8(1.0)$ & & & \\
\hline \multirow[t]{2}{*}{ REMS } & Placebo & 97.7 (7.6) & $12.0(3.4)$ & $19.5(2.7)$ & $20.0(4.3)$ & 33.7 (4.9) & $0.01(.93)$ & $5.8(.02)$ & $3.8(<.06)$ \\
\hline & SR 46349B & $85.6(4.6)$ & $9.0(1.7)$ & $26.9(3.1)$ & $27.5(3.5)$ & $20.8(2.5)^{d}$ & & & \\
\hline \multirow[t]{2}{*}{ MT } & Placebo & $8.5(0.9)$ & $1.2(0.2)$ & $1.5(0.2)$ & $1.9(0.4)$ & $2.3(0.3)$ & $21.5(<.01)$ & $3.9(.04)$ & $0.8(.47)$ \\
\hline & SR 46349B & $5.1(0.4)^{c}$ & $0.6(0.2)^{a}$ & $1.0(0.2)$ & $1.6(0.3)$ & $1.3(0.3)^{a}$ & & & \\
\hline \multirow[t]{2}{*}{$\mathrm{W}+\mathrm{MT}+1$} & Placebo & $68.7(7.6)$ & $7.5(2.3)$ & $10.6(2.2)$ & 11.9 (1.3) & $23.1(6.5)$ & $2.3(.17)$ & $4.7(.04)$ & $1.5(.25)$ \\
\hline & SR 46349B & $49.2(4.9)$ & $3.8(0.8)$ & $9.0(1.2)$ & $13.9(2.3)$ & $16.0(3.8)$ & & & \\
\hline \multirow[t]{2}{*}{ Heart rate } & Placebo & 53.9 (1.7) & $54.7(1.8)$ & $53.8(1.8)$ & $53.0(1.8)$ & $53.6(1.8)$ & $0.7(.42)$ & $4.0(.07)$ & $0.2(.70)$ \\
\hline & SR 46349B & $52.9(1.7)$ & $54.4(2.0)$ & 53.5 (1.7) & 51.9 (1.6) & $52.1(1.7)$ & & & \\
\hline
\end{tabular}

Values represent means (SEM) of 10 subjects. NREM-Ep., NREMS episode; REM-Ep., REMS episode; WASO, wakefulness after sleep onset; Stage 1, Stage 2, Stage 3, Stage 4: NREMS stages 1-4; SWS, slow wave sleep (stages $3+4$ ); SWA, slow-wave activity (EEG power density in the $0.75-4.5 \mathrm{~Hz}$ range); MT, movement time; $\mathrm{W}+\mathrm{MT}+1$, accumulated values of wakefulness after sleep onset, movement time and stage 1 .

$F$ and $p$ values: rANOVA with the within factors 'treatment' (placebo, SR 46349B) and 'cycle' (1-4).

${ }^{a} p<.05$.

${ }^{b} p<.01$.

${ }^{c} p<.001$ compared to placebo (rANOVA with within factor 'treatment').

${ }^{d}$ Two subjects were awakened in REMS prior to the completion of the fourth NREM-REMS cycle (VP \#8 and VP \#10) after intake of SR 46349B. In the fourth cycle, their data were excluded from the calculation of mean values for Cycle length, REM-Ep. and REMS. 
Table 2. All-night sleep variables

\begin{tabular}{lrrc}
\hline Variable & Placebo & SR 46349B & $\begin{array}{c}\text { 'Treatment' } \\
\mathbf{F}_{\mathbf{1 , 8}}(p)\end{array}$ \\
\hline SL_EP (min) & $461.5(5.2)$ & $460.6(5.3)$ & $0.0(.86)$ \\
TST (min) & $440.9(7.2)$ & $450.2(6.8)$ & $1.0(.34)$ \\
SL_EFF (\%) & $91.9(1.5)$ & $93.8(1.4)$ & $1.0(.34)$ \\
L1 (min) & $11.8(4.1)$ & $15.8(4.5)$ & $1.2(.32)$ \\
SL (min) & $14.3(4.0)$ & $17.9(4.7)$ & $0.4(.54)$ \\
RL (min) & $65.8(5.2)$ & $68.6(3.3)$ & $0.7(.43)$ \\
WASO (\%) & $3.9(1.6)$ & $1.6(0.6)$ & $1.6(.25)$ \\
Stage 1 (\%) & $9.9(1.0)$ & $8.3(0.8)$ & $4.9(.06)$ \\
Stage 2 (\%) & $49.2(1.9)$ & $40.9(2.1)$ & $12.9(<0.01)$ \\
Stage 3 (\%) & $10.2(0.9)$ & $17.2(1.2)$ & $33.1(<0.01)$ \\
Stage 4 (\%) & $8.4(1.0)$ & $14.6(1.7)$ & $28.0(<0.01)$ \\
SWS (\%) & $18.6(1.0)$ & $31.8(2.1)$ & $65.0(<0.01)$ \\
REMS (\%) & $22.2(1.9)$ & $19.0(1.0)$ & $6.9(.03)$ \\
MT (\%) & $1.9(0.2)$ & $1.1(0.1)$ & $22.7(<.01)$ \\
W + MT + 1 $(\%)$ & $15.7(1.9)$ & $11.0(1.2)$ & $4.2(.07)$ \\
\hline
\end{tabular}

Values represent means (SEM) of 10 subjects. SL_EP, sleep episode (time between sleep onset and final awakening); TST, total sleep time; SL_EFF, sleep efficiency (TST/TIB $\times 100$ ); TIB, time in bed; L1, Latency to Stage 1 (time from lights-off to the first occurrence of Stage 1); SL, Sleep latency (time from lights-off to the first occurrence of Stage 2); RL, REM latency (time from sleep onset to the first occurrence of REM sleep); other variables are explained in legend of Table 1.

$F$ and $p$ values: rANOVA with the within factor 'treatment' (placebo, SR 46349B).

range. The major peak was situated at $1.5 \mathrm{~Hz}$ and a secondary peak at $6 \mathrm{~Hz}$. Within the $11.25-14.0 \mathrm{~Hz}$ and $15.25-19.0 \mathrm{~Hz}$ range, the drug values were below the placebo level, the minimum corresponding to the $12.25-14.0 \mathrm{~Hz}$ spindle frequency range. The changes in the spectra were most pronounced in the second and third NREMS episode (data not shown). The spectrum in stage 2 was very similar to that of NREMS with the exception that the enhancement was restricted to the low-frequency range $(\leqslant 3 \mathrm{~Hz})$. In contrast, the SWS spectrum did not exhibit an increase of SWA. Power in the $2.75-3.0 \mathrm{~Hz}$ bin was even below the placebo level. The increased SWA in stage 2 and the absence of an increase in SWS is also evident in the records shown in Figure 1. In REMS, power density was reduced in two bins of the delta band $(2.75-3.25 \mathrm{~Hz})$.

\section{Dynamics of slow-wave activity (SWA) and spindle frequency activity (SFA)}

In both the placebo and drug condition SWA was high in NREMS and low in REMS, and a declining trend was present over consecutive NREMS episodes. In Figure 3 (upper panel) the enhancement of SWA by SR 46349B is evident. This was confirmed by a rANOVA with the within factors 'treatment' (placebo, SR 46349B) and 'timebin' (1-20) which revealed a significant effect of the factor 'treatment' for NREMS episodes 2 and $3\left(\mathrm{~F}_{1,8}=263.5\right.$, $p<.0001$ and $\mathrm{F}_{1,8}=24.1, p<.001$, respectively). A statistical trend for 'treatment' was present for episodes 1 and $4\left(\mathrm{~F}_{1,7}=4.8, p<.07\right.$ and $\left.\mathrm{F}_{1,7}=3.8, p<.1\right)$.

The typical pattern of SFA with low values in REMS episodes, and a higher level, U-shaped pattern in NREMS, was present in both conditions. However, SFA was significantly lower in the drug night in all four NREMS episodes (Figure 3, lower panel; rANOVA, within factor 'treatment': NREM-1: $\mathrm{F}_{1,7}=7.4, p<.03$; NREM-2: $\mathrm{F}_{1,8}=17.8, p<.003 ;$ NREM-3: $\mathrm{F}_{1,8}=15.2$, $p<.005$; and NREM-4: $\left.\mathrm{F}_{1,7}=11.3, p<.02\right)$. The global pattern during the first four NREMS episodes was simi-

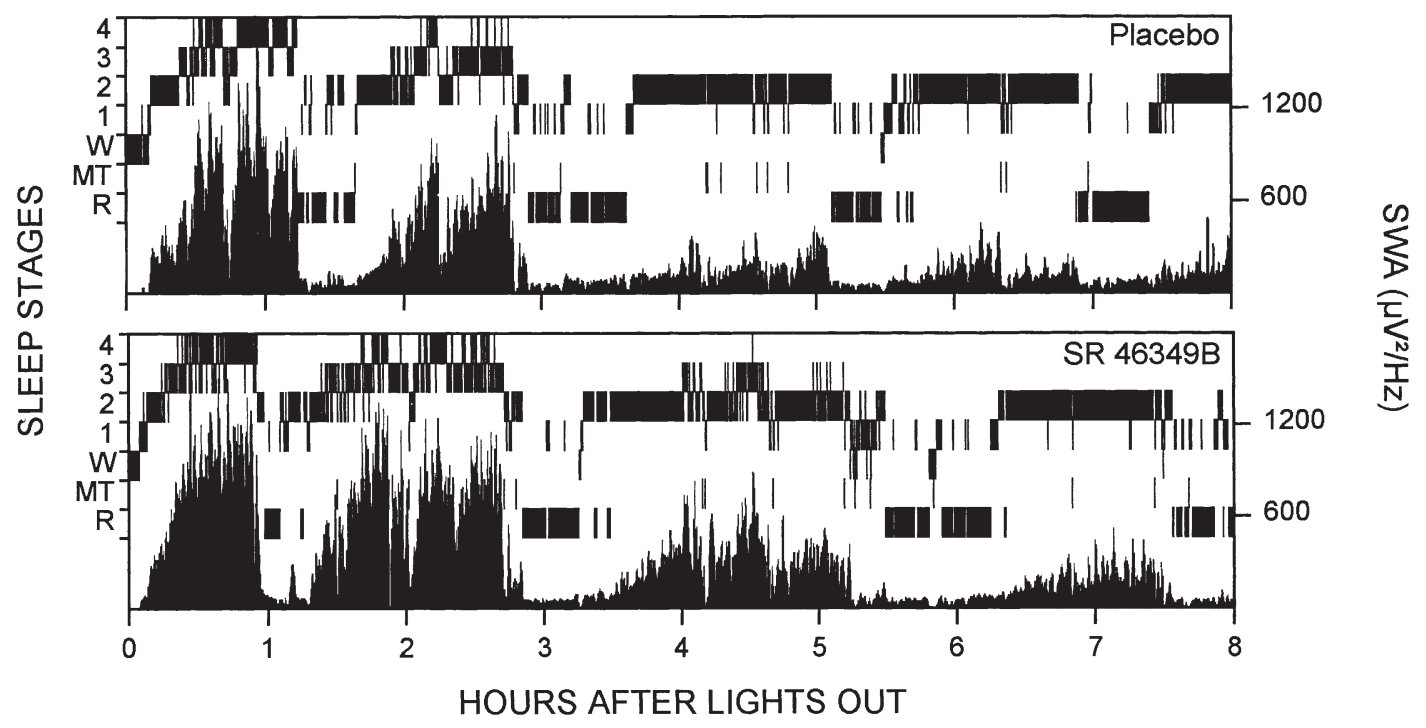

Figure 1. Sleep stages and EEG slow-wave activity (SWA, power density within 0.75-4.5 Hz; C3A2-derivation) of a subject after intake of placebo (upper panel) and SR 46349B (lower panel). 1, 2, 3, and 4: NREMS stages 1-4; W, wakefulness; MT, movement time; R, REMS. The curves of SWA were smoothed by a three-point moving average. 


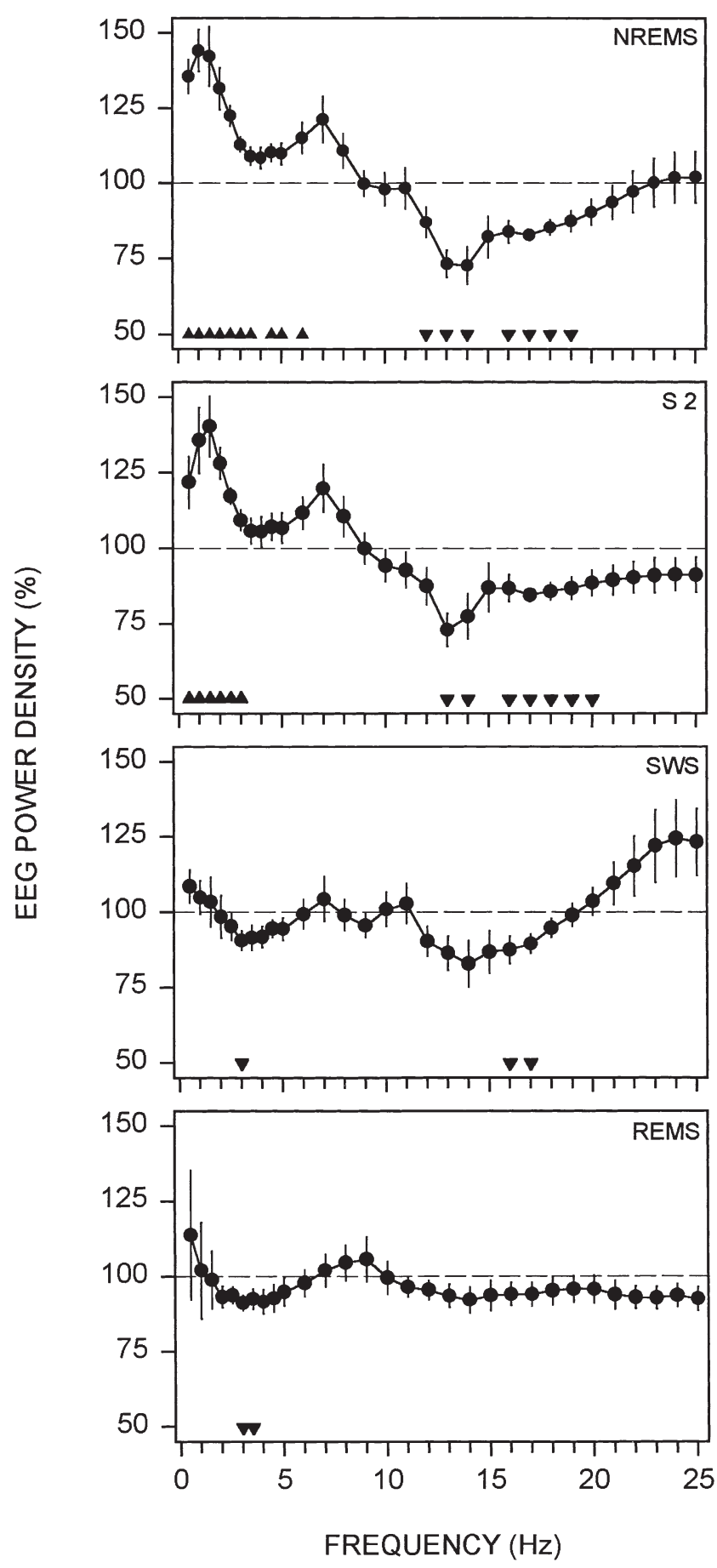

Figure 2. EEG power density (C3A2-derivation) in nonREM sleep (NREMS, stages 2, 3, and 4), stage 2 (S2), slow wave sleep (SWS, stages 3 and 4 ) and REM sleep (REMS) after SR 46349B administration. For each frequency bin $(\bullet$, $\pm 1 \mathrm{SEM}, n=10)$, means were expressed as a percentage of the corresponding value after placebo (horizontal dashed lines at $100 \%$ ). Values are plotted at the upper limit of the bins. Triangles at the bottom of the panels indicate frequency bins which differed significantly from placebo $(p<$ .05 , rANOVA with within factor 'treatment'); their orientation indicates the direction of deviation from placebo. lar in both conditions (rANOVA on mean episodic SFA values: 'treatment' $\times$ 'episode': $\mathrm{F}_{3,24}=2.1$, n.s.).

\section{Evolution of SWA and SFA in the first four NREMS episodes}

The build-up of SWA and SFA in the first part of NREMS episodes, and the decline in the final part of the episodes, are illustrated in Figure 4. Values for consecutive 2-min epochs are plotted for the first and last 30 min of each episode. For each 30-min interval a significant effect of '2-min epoch' was revealed by rANOVA for SWA and SFA (data not shown). SWA values of several 2-min bins of episodes 2, 3, and 4 were higher after drug treatment than after placebo. To analyze the rise rate of SWA, the median of the differences of adjacent 2 -min values was computed for the interval from -2 min to $+20 \mathrm{~min}$ for each NREMS episode. A significantly higher rise rate was observed for the drug condition in the second (6.4 vs. $19.8 \% / 2 \mathrm{~min}$ ) and fourth episodes ( 2.0 vs. $3.9 \% / 2 \mathrm{~min}$; rANOVAs with within factor 'treatment: $\mathrm{F}_{1,8}=10.7, p<.02$ and $\mathrm{F}_{1,8}=25.7, p<.01$, respectively), and a similar tendency prevailed in the third episode (5.1 vs. 8.5\%/2 min, $\mathrm{F}_{1,8}=3.4, p=.1$ ).

SFA showed a rapid initial rise reaching the peak value after 5-10 min after the onset of NREMS, and decreased thereafter. In the last $30 \mathrm{~min}$ of NREMS, a transient increase preceded occasionally the sharp decline in the first three NREMS episodes. This typical time course of SFA was preserved after drug administration (rANOVA: 'treatment' $\times$ '2-min epoch', $p \geqslant .09$ in the initial and final $30 \mathrm{~min}$ of the first four NREMS episodes). Nevertheless, the SFA values were below the placebo level in several 2-min epochs as shown by the statistics in Figure 4.

\section{Regional differences of the EEG spectra}

The six panels on the right side of Figure 5 show the relative NREMS spectra of the drug night for three bipolar derivations along the antero-posterior axis recorded from the left and right hemisphere. Absolute spectra averaged over both hemispheres are shown in the left column of the figure. The pattern of changes seen for the referential derivation (Figure 2) was present also for the bipolar derivations. It consisted of a main peak in the low delta band, a secondary peak around $6 \mathrm{~Hz}$ and a trough at $13 \mathrm{~Hz}$. Significant deviations from placebo are indicated by the F-values at the bottom of the panels (rANOVA with within factor 'treatment').

The regional differences of the bipolar derivations along the antero-posterior axis are indicated in Figure 6 where the mean values of the middle $(\mathrm{CP})$ and posterior derivations (PO) are expressed as a percentage of the anterior derivation (FC). The F-values of a rANOVA with the within factors 'A-P derivation' (FC, CP, PO), 'L-R derivation' (left hemisphere, right hemisphere) 
Placebo
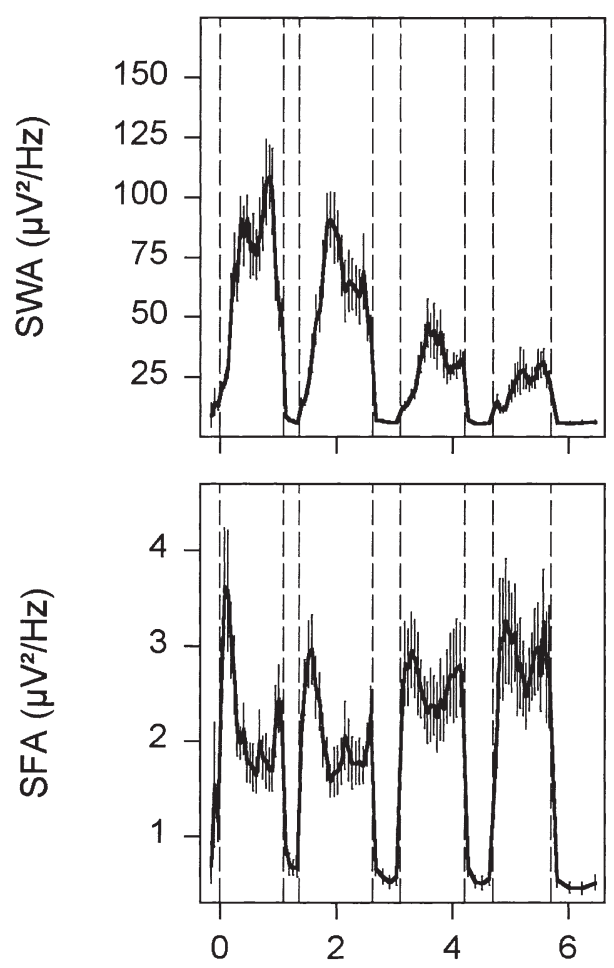

SR 46349B
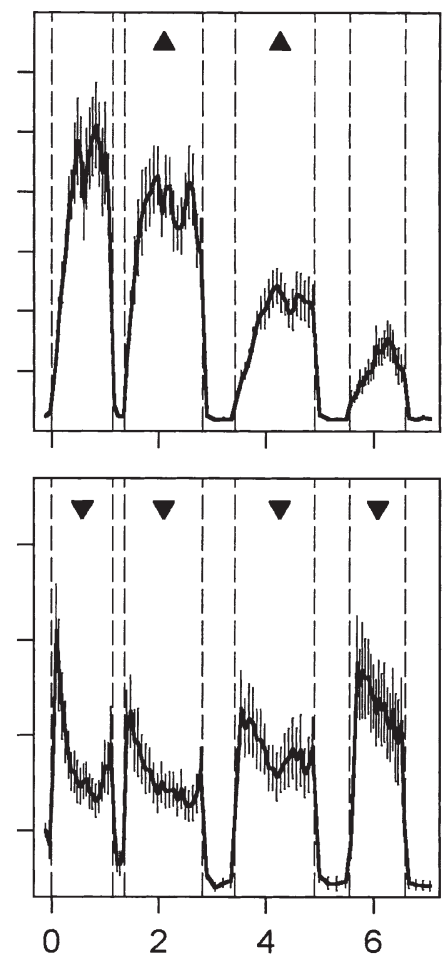

Figure 3. Time course of EEG slow-wave activity (SWA, 0.75-4.5 Hz range; C3A2derivation) and spindle frequency activity (SFA, 12.25-15.0 Hz range; C3A2-derivation) plotted after treatment with placebo (left) and SR 46349B (right). For each subject, individual NREMS episodes were subdivided into 20 equal time-bins, and REMS episodes as well as the interval between lights-out and sleep onset were subdivided into four equal time-bins. Data were averaged across subjects $(n=10)$ and plotted against the mean timing of NREMS and REMS. Vertical bars represent \pm 1 SEM and dashed vertical lines delimit REMS episodes. Triangles indicate NREMS episodes with a significant 'treatment' effect (see text for statistics); orientation of the triangles indicates the direction of deviation from placebo.

\section{HOURS AFTER SLEEP ONSET}

and 'treatment' confirm that significant regional differences prevail in the $1.125-2.0 \mathrm{~Hz}$ and $4.375-14.5 \mathrm{~Hz}$ range (Figure 6, middle panel). Although the regional differences were similar for the placebo and drug condition, a significant interaction 'treatment' $\times$ 'A-P derivation' was present in the $9.125-12.0 \mathrm{~Hz}$ range as well as in most bins within the $13.375-16.0 \mathrm{~Hz}$ band. The latter was due to the anterior shift of power in these frequency bins. The interaction 'treatment' $\times$ 'L-R derivation' (hemispheres) and the 3-way interaction 'treatment' $\times$ 'A-P derivation' $\times$ 'L-R derivation' were not significant.

\section{Core body temperature}

Rectal temperature declined in the first 6 hours of sleep and showed an increasing trend in the last 2 hours (Figure 7). However, temperature was lower in the drug night than in the placebo night. The difference of the mean values in hour $5-6$ was $0.24^{\circ} \mathrm{C}$. A rANOVA with the within factors 'treatment' and 'hour' (1-8) revealed significant effects of 'treatment' $\left(\mathrm{F}_{1,6}=6.3, p<.05\right)$ and 'hour' $\left(\mathrm{F}_{7,42}=10.1, p<0.004\right.$; 'treatment' $\times$ 'hour': $\mathrm{F}_{7,42}=0.7$, n.s. $)$.

\section{DISCUSSION}

The present study shows that a single oral dose of $1 \mathrm{mg}$ SR 46349B, a potent and selective $5-\mathrm{HT}_{2}$ receptor antag- onist, affects the sleep stages and EEG power spectra of young healthy men. The principal effect consisted of a massive increase of SWS and SWA. Similar changes had been reported for the less selective $5-\mathrm{HT}_{2}$ antagonists ritanserin and seganserin (Idzikowski et al. 1986; Declerck et al. 1987; Borbély et al. 1988; Dijk et al. 1989). In previous studies, also a $10-\mathrm{mg}$ dose of the $5-\mathrm{HT}_{1 \mathrm{~A}}$ agonist ipsapirone enhanced SWA in the first two hours of NREMS (Seifritz et al. 1996), yet did not increase SWS (Gillin et al. 1994, 1996). The effects of ipsapirone on EEG power spectra in NREMS were remarkably similar to those induced by seganserin (Seifritz et al. 1996). These results and single unit recordings (Ashby et al. 1994) support the notion that inhibitory $5-\mathrm{HT}_{1 \mathrm{~A}}$ receptors and excitatory $5-\mathrm{HT}_{2}$ receptors mediate opposite changes. Unlike ritanserin (Borbély et al. 1988), seganserin (Dijk et al. 1989), and ipsapirone (Tissier et al. 1993; Gillin et al. 1994, 1996; Driver et al. 1995), SR 46349B did not influence the amount and the latency to REMS.

Hypothermia is also a well-known effect of the $5-\mathrm{HT}_{1 \mathrm{~A}}$ agonist ipsapirone (Lesch et al. 1990). The slight hypothermia induced by SR 46349B demonstrates that the $5-\mathrm{HT}_{1 \mathrm{~A}}$ and $5-\mathrm{HT}_{2}$ receptors mediate opposite changes also at the level of thermoregulation.

There were striking similarities between the effects of SR 46349B and those induced by sleep deprivation (SD). Specifically, after both interventions: 1) the maximum increase of delta frequency activity was at $1.5 \mathrm{~Hz}$ 


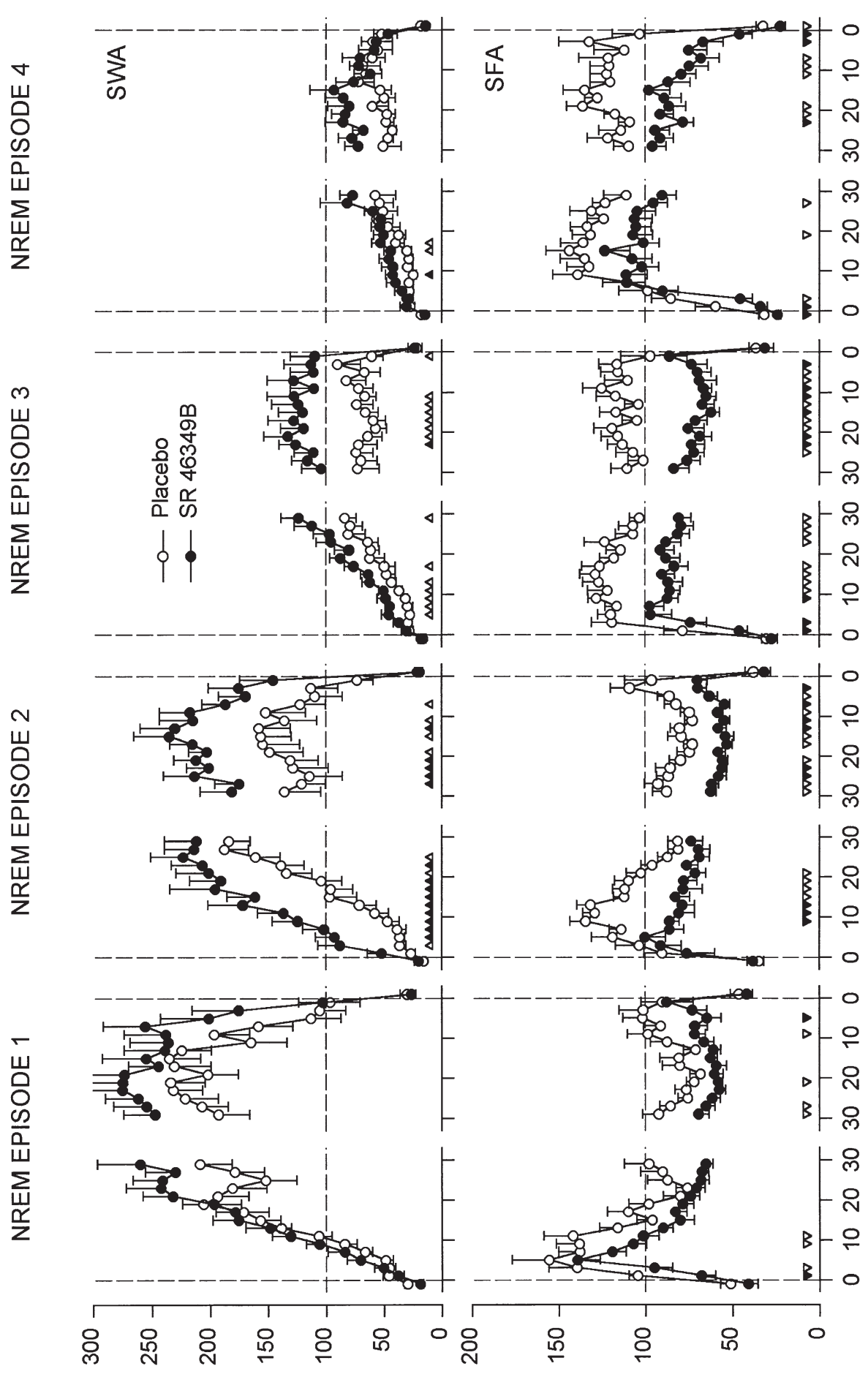

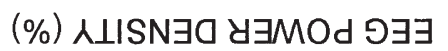

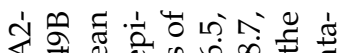
仓ै

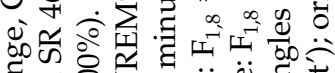

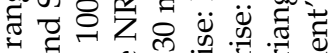

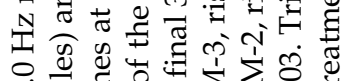

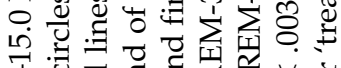
눙 ฮี ฮี ปิ ये ত 纯苟

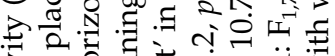

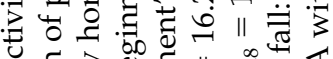

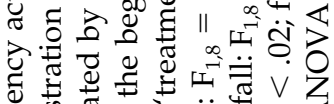

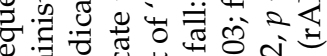
छ

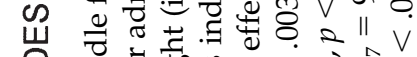

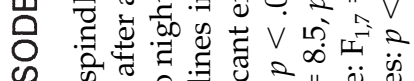
क के के ш वे छ ठ.

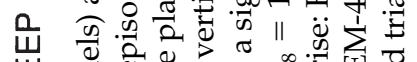

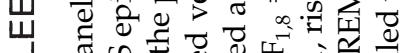

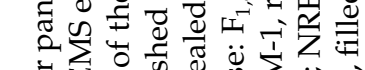

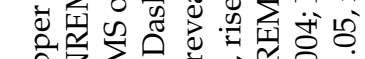
学 $\sum_{i=1}^{\infty} a$ i

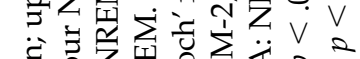

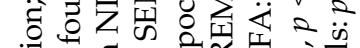

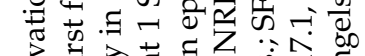

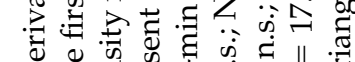
एँ

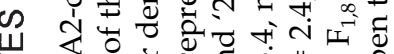
ए $\sum$

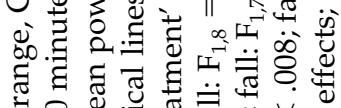
N एव

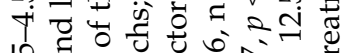

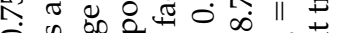
$\circ$ \&

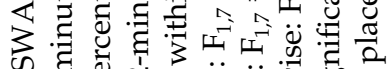
क्र द्व रिक

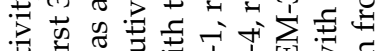

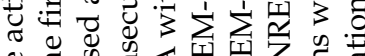

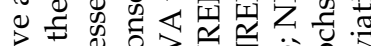

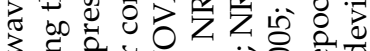
३ द्व

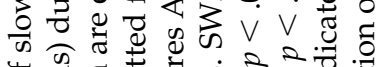

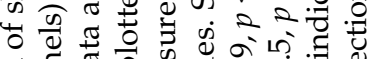

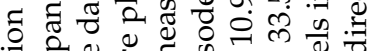
考它号 깅

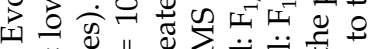

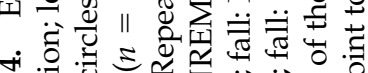
+ं

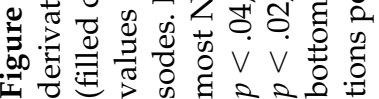




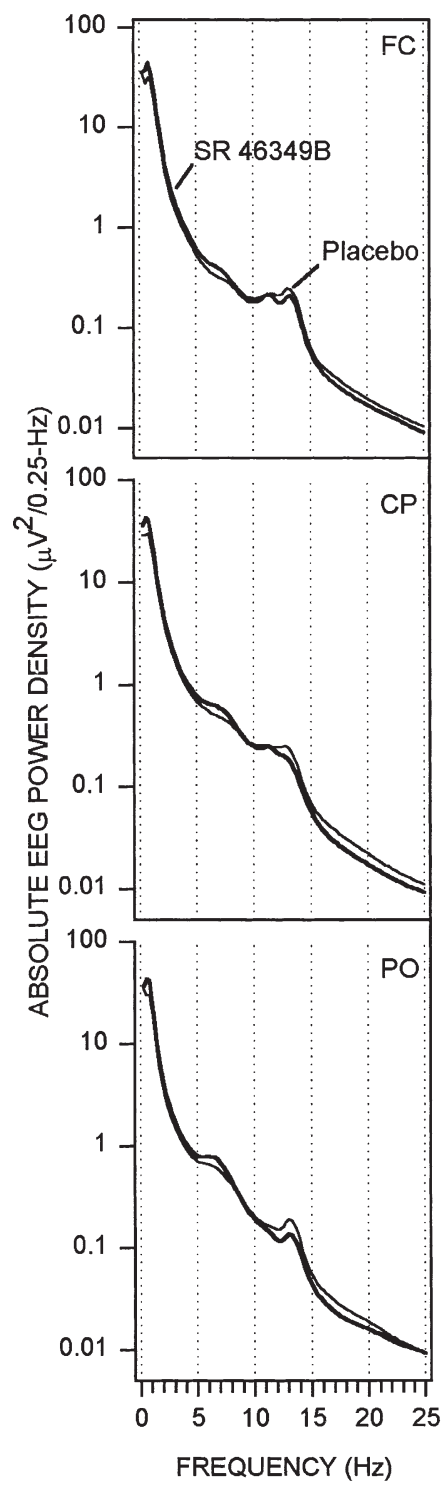

RELATIVE EEG POWER DENSITY (\%)
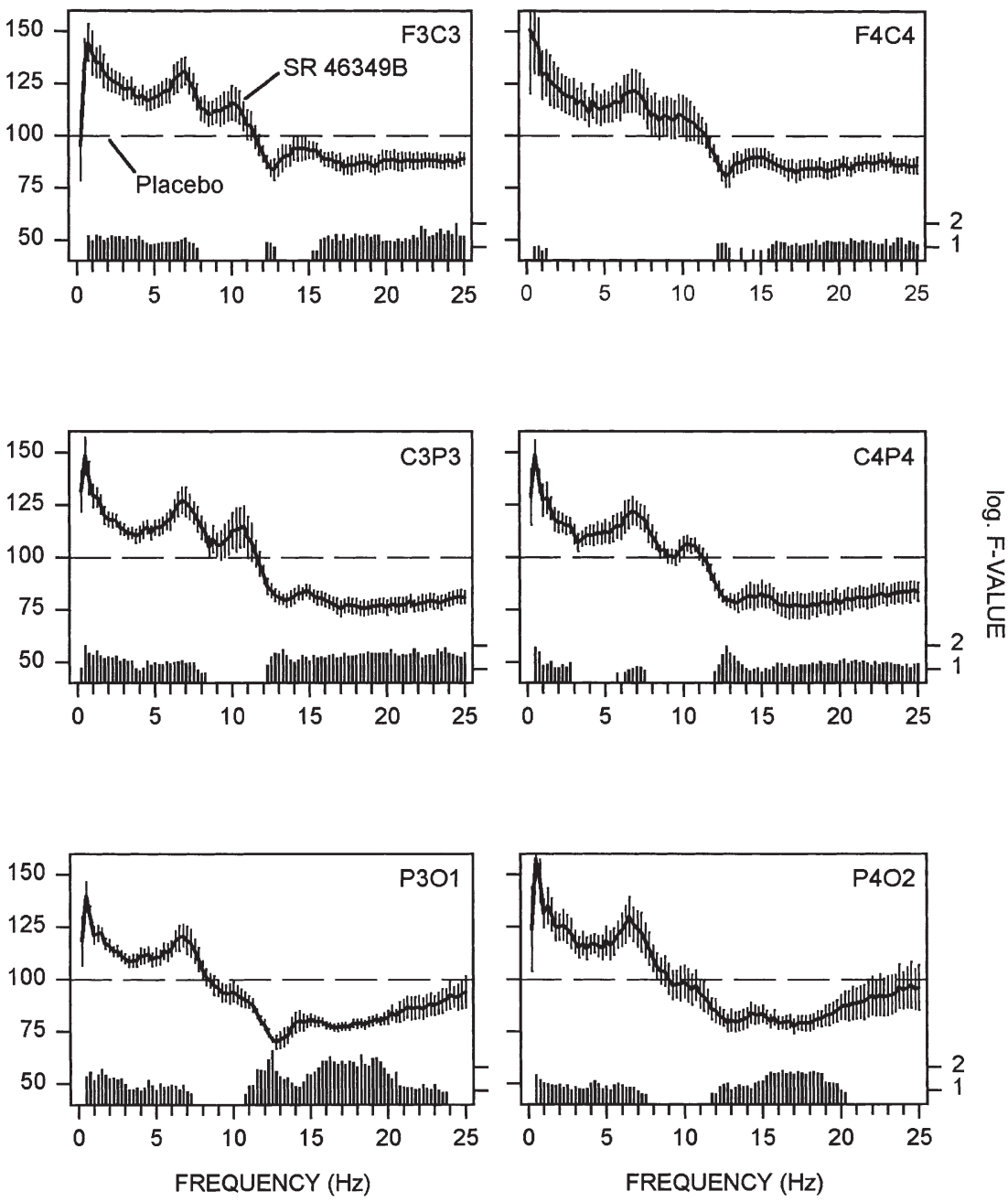

Figure 5. All-night EEG power spectra of bipolar derivations along the antero-posterior axis. Power density values for each frequency bin are expressed as $\mu \mathrm{V}^{2} / 0.25 \mathrm{~Hz}$ (left; placebo: thin line, SR 46349B: thick line; values averaged over left and right hemispheres), or as a percentage of the corresponding value after placebo (right; vertical lines represent \pm 1 SEM, $n=8$ ). Mean values are plotted in the middle of the bins. Vertical bars above the abscissae represent significant log. F-values of a rANOVA on log-transformed absolute power density values with the within factor 'treatment' $(d f=1,6)$.

(SD: Borbély et al. 1981, 1984; Dijk et al. 1990, 1993; Tobler and Borbély 1990; Aeschbach et al. 1996) (SR 46349B: Figure 2); 2) the build-up rate of SWA within NREMS episodes was increased (SD: Dijk et al. 1993; Aeschbach et al. 1996) (SR 46349B: Figure 4); and 3) SFA was reduced (SD: Borbély et al. 1981; Dijk et al. 1990, 1993) (SR 46349B: Figures 3 and 4). These findings suggest that $5-\mathrm{HT}_{2 \mathrm{~A}}$ receptors are involved in the regulation of SWS. However, since the selective specificity of SR 46349B for 5- $\mathrm{HT}_{2 \mathrm{~A}}$ receptors has been so far demonstrated only in rodents (Rinaldi-Carmona et al. 1992), this aspect needs to be confirmed in humans.
There were also differences from the physiological effects. For one, unlike the typical unimodal increase of power in the delta and theta band following prolonged waking, the relative spectra of the present study had a bimodal appearance with a trough at $3.5-5 \mathrm{~Hz}$. The trough appears to be a state independent feature, since it was present in both SWS and REMS (Figure 2). An association of this bimodal spectral pattern with the serotonergic system is supported by the observation that it is common to both $5-\mathrm{HT}_{2}$ antagonists, i.e., seganserin in humans (Dijk et al. 1989) and ritanserin in rats (Borbély et al. 1988), and $5-\mathrm{HT}_{1 \mathrm{~A}}$ agonists, i.e., ipsapirone (Sei- 


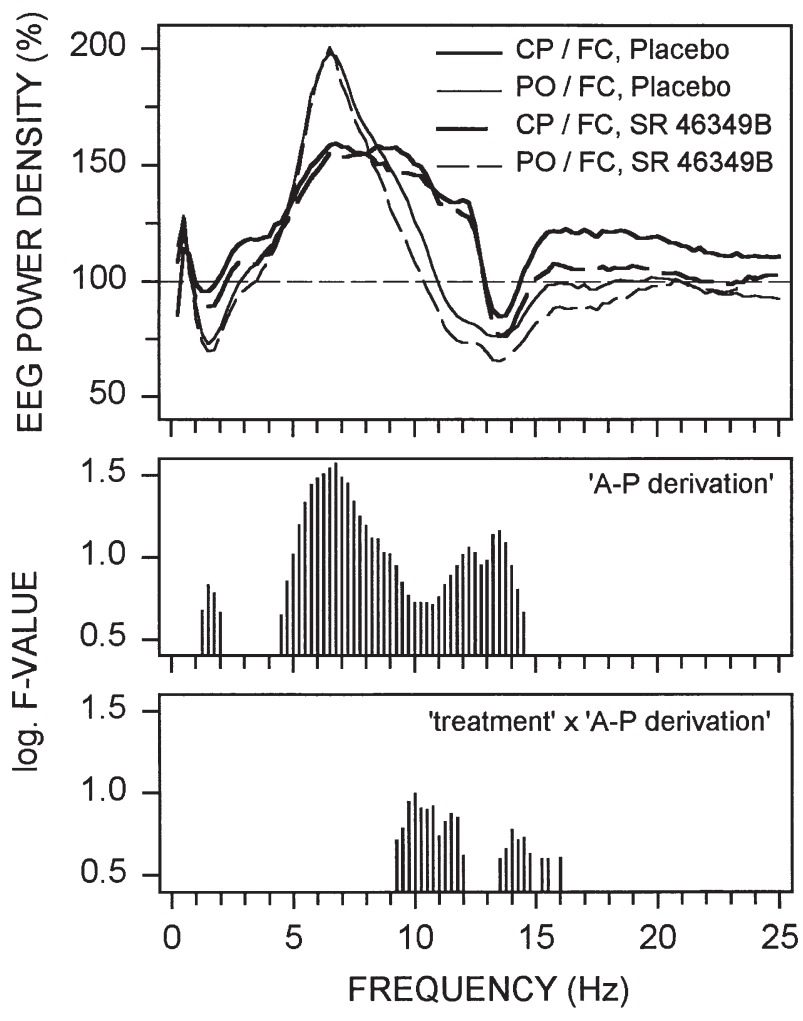

Figure 6. Regional differences of all-night power spectra in NREMS (stages 2, 3, and 4) along the antero-posterior axis after placebo (continuous lines) and SR 46349B (interrupted lines). Top panel: For each frequency bin, power density values in the central (thick lines) and parietal (thin lines) derivations are expressed as a percentage of the corresponding values in the frontal derivation $(100 \%)$. Mean values over the left and right hemispheres are plotted in the middle of the bins. Bottom panels: Vertical bars represent significant $\log$. F-values of a rANOVA on log-transformed absolute power density values with the within factors 'treatment' $(d f=1,6)$, 'A-P derivation' (FC, CP, PO; $d f=2,12)$, and 'L-R derivation' (left hemisphere, right hemisphere; $d f=1,6$ ).

fritz et al. 1996). Another difference from the physiological changes was that low-frequency EEG activity was increased only in stage 2 (Figure 2), whereas prolonged waking had been shown to enhance SWA also in SWS and REMS (Borbély et al. 1981). Moreover, unlike after recovery from $\mathrm{SD}$, the second and third NREMS episodes were prolonged. This suggests that antagonism at $5-\mathrm{HT}_{2}$ receptors promotes the maintenance of synchronized EEG activity without enhancing maximal SWA beyond the usual level. The reduction of SFA at the expense of SWA seems to reflect the promotion of 'deep NREMS'. The finding that NREMS does not appear to be intensified beyond the baseline level is in accordance with the observation that sleep was not perceived to be deeper than usual.

Different effects at the level of 5-HT receptors may be responsible for the discrepancies between physiolog-

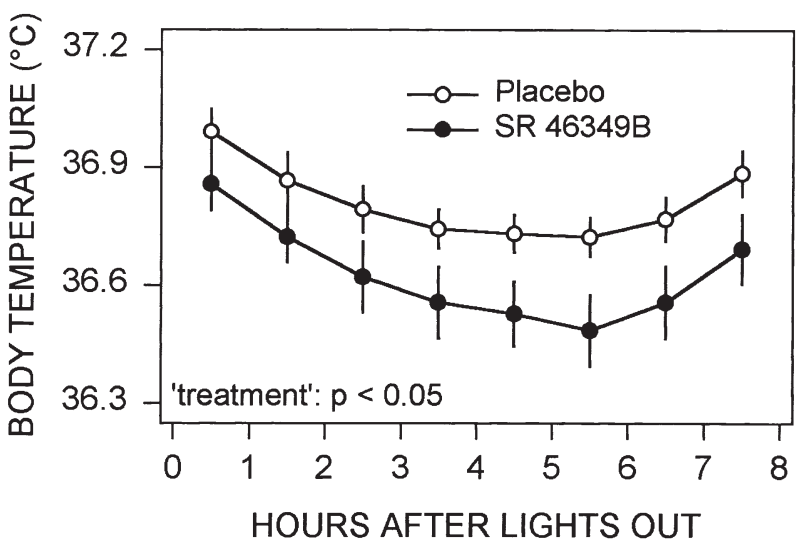

Figure 7. Time course of rectal temperature after administration of placebo (open circles) and SR 46349B (filled circles). Mean values $(n=8)$ are plotted in the middle of consecutive 1-hour intervals; vertical lines represent \pm 1 SEM. A rANOVA with the within factors 'treatment' and 'hour' revealed a significant 'treatment' effect $\left(\mathrm{F}_{1,6}=6.03\right.$, $p<.05)$.

ical and pharmacological effects. In the present study, blockade of $5-\mathrm{HT}_{2}$ binding sites may have prevented depolarization of thalamocortical neurons by their natural ligand (McCormick 1992; Bobker 1994), and prolonged burst-pause firing and EEG synchronization. In contrast, due to continued 5-HT release during wakefulness (Portas et al. 1998), the serotonergic system may be desensitized after SD. Functional desensitization of endogenous $5-\mathrm{HT}_{2}$ receptors associated with a partial down-regulation of receptor number has been demonstrated recently in vitro after treatment with 5-HT (Saucier et al. 1998).

The topographic analysis along the antero-posterior axis revealed robust derivation effects that correspond to those reported previously (Werth et al. 1997). The typical drug-induced changes were evident in all bipolar derivations. Nevertheless, the subtle yet significant interactions between treatment and derivation showed that the compound did affect the spatial distribution of EEG power. Interestingly, the significant interaction included not only the frequency range around $15 \mathrm{~Hz}$ in which drug-induced changes were manifest, but also frequencies at $10 \mathrm{~Hz}$ where no significant treatment effects were seen. These selective changes may be related to the regional distribution of cortical $5-\mathrm{HT}_{2}$ receptors (Pazos et al. 1987) and demonstrate that the spatio-temporal analysis of the sleep EEG may disclose novel effects in pharmacological studies.

In conclusion, the antagonism of $5-\mathrm{HT}_{2}$ receptors mimics the effects of sleep deprivation by enhancing SWA and attenuating SFA. However, unlike after prolonged waking, it is the duration of the NREMS fraction dominated by high SWA, which is increased, rather 
than NREMS intensity as reflected by the level of SWA in SWS (Figure 2). Moreover, perceived sleep intensity is not augmented. The $5-\mathrm{HT}_{2}$ receptor antagonist induces a bimodal pattern in the NREMS spectrum which differs from the unimodal pattern seen after sleep deprivation. The bimodality is caused by a state independent reduction of power at 2-3 Hz. This effect has been reported for other $5-\mathrm{HT}_{2}$ receptor antagonists, as well as for a $5-\mathrm{HT}_{1 \mathrm{~A}}$ agonist. Hypothermia may represent a similar common feature of 5- $\mathrm{HT}_{2}$ antagonists and $5-\mathrm{HT}_{1 \mathrm{~A}}$ agonists. The present results show that altering the balance between $5-\mathrm{HT}_{2}$ and $5-\mathrm{HT}_{1 \mathrm{~A}}$ receptor activity may be necessary, but is not sufficient, for inducing the changes in the EEG spectrum which are typically seen after sleep deprivation.

\section{ACKNOWLEDGMENTS}

We thank Dr. Corinne Roth for her assistance with the experiment and Dr. Irene Tobler for comments on the manuscript. This research was supported by SANOFI Recherche, the Swiss National Science Foundation (Grant Nr. 3100-042500.94 and 3100-053005.97) and the Human Frontiers Science Program RG 81/96.

\section{REFERENCES}

Adrien J (1995): The serotoninergic system and sleep-wakefulness regulation. In Kales A (ed), The Pharmacology of Sleep. New York, Springer, pp 91-116

Aeschbach D, Cajochen C, Landolt HP, Borbély AA (1996): Homeostatic sleep regulation in habitual short and long sleepers. Am J Physiol 270:R41-R53

Ashby CR Jr., Edwards E, Wang RY (1994): Electrophysiological evidence for a functional interaction between $5-\mathrm{HT}_{1 \mathrm{~A}}$ and $5-\mathrm{HT}_{2 \mathrm{~A}}$ receptors in the rat medial prefrontal cortex: An iontophoretic study. Synapse 17:173-181

Bobker DH (1994): A slow excitatory postsynaptic potential mediated by $5-\mathrm{HT}_{2}$ receptors in nucleus prepositus hypoglossi. J Neurosci 14:2428-2434

Borbély AA, Baumann F, Brandeis D, Strauch I, Lehmann D (1981): Sleep deprivation: Effect on sleep stages and EEG power density in man. Electroenceph Clin Neurophysiol 51:483-493

Borbély AA, Tobler I, Hanagasioglu M (1984): Effect of sleep deprivation on sleep and EEG power spectra in the rat. Behav Brain Res 14:171-182

Borbély AA, Tononi G (1998): The quest for the essence of sleep. Daedalus. Proc Am Acad Arts Sci 127:167-196

Borbély AA, Trachsel L, Tobler I (1988): Effect of ritanserin on sleep stages and sleep EEG in the rat. Eur J Pharmacol 156:275-278

Declerck AC, Wauquier A, Van der Ham-Veltman PHM, Gelders Y (1987): Increase in slow-wave sleep in humans with the serotonin- $S_{2}$ antagonist ritanserin. The first exploratory polygraphic sleep study. Curr Ther Res Clin Exp 41:427-432
Dijk DJ, Beersma DGM, Daan S, van den Hoofdakker RH (1989): Effects of seganserin, a 5- $\mathrm{HT}_{2}$ antagonist, and temazepam on human sleep stages and EEG power spectra. Eur J Pharmacol 171:207-218

Dijk DJ, Brunner DP, Borbély AA (1990): Time course of EEG power density during long sleep in humans. Am J Physiol 258:R650-R661

Dijk DJ, Hayes B, Czeisler CA (1993): Dynamics of electroencephalographic sleep spindles and slow wave activity in men: Effect of sleep deprivation. Brain Res 626:190199

Driver HS, Flanigan MJ, Bentley AJ, Luus HG, Shapiro CM, Mitchell D (1995): The influence of ipsapirone, a 5- $\mathrm{HT}_{1 \mathrm{~A}}$ agonist, on sleep patterns of healthy subjects. Psychopharmacology 117:186-192

Feinberg I, Floyd TC (1979): Systematic trends across the night in human sleep cycles. Psychophysiology 16:283291

Gillin JC, Jernajczyk W, Valladares-Neto D, Golshan S, Lardon M, Stahl SM (1994): Inhibition of REMS by ipsapirone, a 5- $\mathrm{HT}_{1 \mathrm{~A}}$ agonist, in normal volunteers. Psychopharmacology 116:433-436

Gillin JC, Sohn JW, Stahl SM, Lardon M, Kelsoe J, Rapaport M, Ruiz C, Golshan S (1996): Ipsapirone, a 5-HT 1 agonist, suppresses REMS equally in unmedicated depressed patients and normal controls. Neuropsychopharmacology 15:109-115

Hoyer D, Martin GR (1996): Classification and nomenclature of 5-HT receptors: A comment on current issues. Behav Brain Res 73:263-268

Humphrey PPA, Hartig P, Hoyer D (1993): A proposed new nomenclature for 5-HT receptors. Trends Pharmacol Sci 14:233-236

Idzikowski C, Mills FJ, Glennard R (1986): 5-Hydroxytryptamine-2 antagonist increases human slow wave sleep. Brain Res 378:164-168

Jouvet M (1972): The role of monoamines and acetylcholinecontaining neurons in the regulation of the sleep-waking cycle. Ergebn Physiol 64:166-307

Lesch KP, Poten B, Söhnle K, Schulte HM (1990): Pharmacology of the hypothermic response to 5-HT1A receptor activation in humans. Eur J Clin Pharmacol 39:17-19

McCormick DA (1992): Neurotransmitter actions in the thalamus and cerebral cortex and their role in neuromodulation of thalamocortical activity. Prog Neurobiol 39:337-388

McCormick DA, Bal T (1997): Sleep and arousal: Thalamocortical mechanisms. Annu Rev Neurosci 20:185-215

McCormick DA, Wang Z (1991): Serotonin and noradrenaline excite GABAergic neurons of the guinea pig and cat nucleus reticularis thalami. J Physiol 442:235-255

Pazos A, Probst A, Palacios JM (1987): Serotonin receptors in the human brain. IV. Autoradiographic mapping of serotonin-2 receptors. Neuroscience 21:123-239

Portas CM, Bjorvatn B, Fagerland S, Grønli S, Mundal V, Sørensen E, Ursin R (1998): On-line detection of extracellular levels of serotonin in dorsal raphe nucleus and frontal cortex over the sleep/wake cycle in the freely moving rat. Neuroscience 83:807-814 
Rechtschaffen A, Kales A (eds) (1968): A Manual of Standardized Terminology, Techniques and Scoring System for Sleep Stages of Human Sleep. Washington, D.C.: Public Health Service, U.S. Government Printing Office

Rinaldi-Carmona M, Cogny C, Santucci V, Simiand J, Gautret B, Neliat G, Labeeuw B, Le Fur G, Soubrie P, Breliere JC (1992): Biochemical and pharmacological properties of SR 46349B, a new potent and selective 5-hydroxytryptamine ${ }_{2}$ receptor antagonist. J Pharmacol Exp Ther 262:759-768

Saucier C, Morris SJ, Albert PR (1998): Endogenous serotonin-2A and $-2 \mathrm{C}$ receptors in Balb/c-3T3 cells revealed in serotonin-free medium: Desensitization and down-regulation by serotonin. Biochem Pharmacol 56:1347-1357

Schwartz PJ, Wehr TA, Rosenthal NE, Bartko JJ, Oren DA, Luetke C, Murphy DL (1995): Serotonin and thermoregulation: Physiologic and pharmacologic aspects of control revealed by intravenous $\mathrm{m}-\mathrm{CPP}$ in normal human subjects. Neuropsychopharmacology 13:105-115

Seifritz E, Moore P, Trachsel L, Bhatti T, Stahl SM, Gillin JC (1996): The 5- $\mathrm{HT}_{1 \mathrm{~A}}$ agonist ipsapirone enhances EEG slow wave activity in human sleep and produces a power spectrum similar to $5-\mathrm{HT}_{2}$ blockade. Neurosci Lett 209:41-44

Sharpley AL, Elliott JM, Attenburrow M-J, Cowen PJ (1994):
Slow wave sleep in humans: Role of $5-\mathrm{HT}_{2 \mathrm{~A}}$ and $5-\mathrm{HT}_{2 \mathrm{C}}$ receptors. Neuropharmacology 33:467-471

Steriade M, Contreras D, Amzica F (1994): Synchronized sleep oscillations and their paroxysmal developments. Trends Neurosci 17:199-208

Steriade M, McCormick DA, Sejnowski TJ (1993): Thalamocortical oscillations in the sleeping and aroused brain. Science 262:679-685

Tissier MH, Lainey E, Fattaccini CM, Hamon M, Adrien J (1993): Effects of ipsapirone, a 5- $\mathrm{HT}_{1 \mathrm{~A}}$ agonist, on sleep/ wakefulness cycles: Probable post-synaptic action. J Sleep Res 2:103-109

Tobler I, Borbély AA (1990): The effect of 3-h and 6-h sleep deprivation on sleep and EEG spectra of the rat. Behav Brain Res 36:73-78

Werth E, Achermann P, Borbély AA (1997): Fronto-occipital EEG power gradients in human sleep. J Sleep Res 6:102-112

Werth E, Achermann P, Borbély AA (1998): Regional differences in the sleep EEG: Functional implications. Sleep 21(suppl):207

Werth E, Dijk DJ, Achermann P, Borbély AA (1996): Dynamics of the sleep EEG after an early evening nap: Experimental data and simulations. Am J Physiol 271:R501R510 